Quim. Nova, Vol. 31, No. 1, 98-103, 2008

\title{
A THERMOGRAVIMETRIC ANALYSIS OF THE COMBUSTION OF A BRAZILIAN MINERAL COAL
}

\section{Claudionor Gomes da Silva Filho*}

Interunidade em Biotecnologia, Instituto de Ciências Biomédicas, Universidade de São Paulo, Av. Prof. Lineu Prestes, 1730, Cidade Universitária, 05508-900 São Paulo - SP, Brasil

Fernando Eduardo Milioli

Departamento de Engenharia Mecânica, Escola de Engenharia de São Carlos, Universidade de São Paulo, Av. Trabalhador Sãocarlense, 400, 13566-590 São Carlos - SP, Brasil

Recebido em 8/3/07; aceito em 11/7/07; publicado na web em 19/12/07

\begin{abstract}
Knowledge of coal combustion kinetics is crucial for burner design. This work aims to contribute on this issue by determining the kinetics of a particular Brazilian bituminous coal. Non-isothermal thermogravimetry was applied for determining both the preexponential factor and the activation energy. Coal samples of $10 \mathrm{mg}$ and $775 \mu \mathrm{m}$ mean size were used in synthetic air atmospheres $\left(21 \% \mathrm{O}_{2}\right.$ ). Heating rates from 10 to $50{ }^{\circ} \mathrm{C} / \mathrm{min}$ were applied until the temperature reached $850{ }^{\circ} \mathrm{C}$, which was kept constant until burnout. The activation energy for the primary and the secondary combustion resulted, respectively, in $135.1 \mathrm{~kJ} / \mathrm{mol}$ and $85.1 \mathrm{~kJ} / \mathrm{mol}$.
\end{abstract}

Keywords: coal; combustion; kinetics.

\section{INTRODUCTION}

This work presents a study on the combustion of a particular south brazilian mineral coal through thermal analysis. Providing differential conditions are practicised in thermal analysis, it gives data related to chemical kinetics and mass transport which are essentially intrinsic or intra-particle. Therefore, the results of thermal analysis under differential conditions are relevant to any coal combustion system since effects external to the reacting particles are eliminated. Of course, such results must be combined with the transport conditions of a particular combustion system so that the real rates of reaction can be found. In this work intrinsic reaction rate coefficients are obtained for the combustion of coal under differential oxidizing conditions.

Coal is a chemical and physically heterogeneous mineral, containing high fractions of carbon and small fractions of sulfur and nitrogen ${ }^{1}$. The organic matter in coal includes different hydrocarbons, which ultimately define its calorific value and quality $^{2}$. Literature presents different classifications of mineral coals, based on a variety of characteristics (physical, chemical, reactive, botanical, geological, etc) ${ }^{3}$. A widely used classification in reaction engineering is related to coal calorific value, where coals are named, in crescent order of calorific value, as lignites, sub-bituminous, bituminous, semibituminous, semianthracite and anthracite. Brazilian coal is sub-bituminous and bituminous, and present high contents of volatile matter, sulfur and ashes. As pyrolysed, a significat fraction of its mass is released as gases, leaving behind a very porous char. It is well known that high ash low volatile coals burn in a shrinking core mode, while low ash high volatile coals burn in a progressive conversion mode ${ }^{4}$. It seems reasonable to assume that the high ash high volatile brazilian coals shall burn according to a hybrid mode between shrinking core and progressive conversion. In this way combustion would occur mostly in external layers, leaving behind a shell of ashes attached to an unreacted or partially reacted nucleus.

*e-mail: claumes@usp.br
As heated in oxidizing atmospheres, mineral coals loose moisture and volatiles, and both homogeneous combustion of volatiles and heterogeneous combustion of fixed carbon take place. Besides, mineral matter is oxidized giving rise to ashes. The burning stages may be either simultaneous or successive depending on operational conditions, and are affected by heating rate, pressure, temperature and particulate size ${ }^{5}$. Davine et al. ${ }^{6}$ classified the ignition of coal particles as homogeneous (volatile matter) and heterogeneous (solid surface sites). Yong et al. ${ }^{7}$ included a third class named hetero-homogeneous, accounting for the simultaneous ignition of volatile matter and solid surfaces. Crelling et al. ${ }^{8}$ considered two main reactive events taking place during coal combustion, named primary and secondary combustion. The first takes account of the combined devolatilization and simultaneous fixed carbon combustion, while the second takes account of the following fixed carbon combustion alone. Smith et al. ${ }^{9}$ studied the kinetics of combustion of various coals ranging from lignites to low volatile bituminous, and found different activation energies standing for four different regions of combustion related to different ranges of temperature. Cumming ${ }^{10}$ confirmed the findings of Smith et $a l .{ }^{9}$, and proposed a procedure for determining a mean activation energy from the different values found at different ranges of temperature.

Whatever the equipment used for burning coal, reaction rate depends on chemical kinetics and mass transport both external and internal to the particle. There are various resistances to reaction to account for. Those are due to the transport of the reactive gas species through the gas film involving the particle, due to the gas difusion through external layers of ashes, due to the gas difusion through the porous structure of the particle core, and the chemical kinetics resistance ${ }^{4}$. Mass transport external to the particles depend on fluid mechanics, properties of the particles such as size and shape, and concentration of particles. Mass transport internal to the reactive particles depend on intra-particle fluid mechanics, size and physical structure of the particles (porosity and pore structure). Chemical kinetics resistance is mainly defined by process temperature, reacting atmosphere, chemical composition 
and physical structure of the particles (surface areas external and BET), and particle size. In view of the difficulties for distinguishing among different intra-particle reaction resistances, it is common to propose global intrinsic reaction rate coefficients. Such coefficients comprise effects of chemical kinetics, gas diffusion through solid reacted layers, and gas diffusion through the unreacted or partially reacted nucleus of the particle (both gas-gas molecular diffusion and Knudsen diffusion, i.e. transport by molecular collisions in capillary walls).

According to Laurendeau ${ }^{11}$, pore size distribution and the internal surface area of pores determine intrinsic reaction rates of coals. Pore structure is usually classified in three categories, i.e. micropores $(0.4$ to $1.2 \mathrm{~nm}$ ), mesopores (1.2 to $30 \mathrm{~nm}$ ) and macropores (30 to 2960 $\mathrm{nm})$. Experiment suggests that pore size distributions are bimodal, with macropores predominating in low rank coals and micropores predominating in high rank coals. The development of porosity under reaction depends on reaction velocity. When reactions are slower (e.g. involving $\mathrm{CO}_{2}$ ) the difusion of the reactant gas throughout the macropores is prone to be fully accomplished giving rise to both micro and mesopores. Otherwise, faster reactions (e.g. involving $\mathrm{O}_{2}$ ) are prone to occur only in those regions of the pore structure which are more accessible, favoring the development of macropores. In this case no new porosity is generated, but micro and mesopores are transformed into macropores.

Dutta and Wen ${ }^{12,13}$ determined the reactivity of various coals in atmospheres of $\mathrm{CO}_{2}$ and $\mathrm{O}_{2}-\mathrm{N}_{2}$. They observed that the reactive process in $\mathrm{CO}_{2}$ atmosphere occurs in two different stages, i.e. pyrolysis and reaction to $\mathrm{CO}_{2}$. The reactivity during pyrolysis is mainly a function of volatile fraction and heating rate. The reactivity during reaction to $\mathrm{CO}_{2}$ is mainly a function of coal type. Otherwise, the reactivity of coals in $\mathrm{O}_{2}-\mathrm{N}_{2}$ atmosphere is mainly a function of devolatilization extent. In both atmospheres the reactive process seems to be mainly controlled by the advance of porosity under reaction. In $\mathrm{CO}_{2}$ atmosphere the development of porosity is quite diverse for the various coals. In $\mathrm{O}_{2}-\mathrm{N}_{2}$ atmosphere all the coals experiment similar high variation of porosity, and their reactive behavior results closer. Diffusion of $\mathrm{O}_{2}$ through the gas film surrounding the coal particles control reaction for temperatures between 834 and $1106{ }^{\circ} \mathrm{C}$ and $\mathrm{O}_{2}$ gas fractions between 0.2 and 2 $\%$. Maloney et al. ${ }^{14}$ show that in a lower oxygen environment $(6 \%)$ char combustion occurs mostly near the particle surface, while for higher oxygen contents (12\%) the burning advances into the particle interior. Murphy and Shaddix ${ }^{15}$ studied the combustion kinetics of different coal chars in oxygen-enriched environments, in an entrained flow reactor. Increasing kinetics control was observed as the concentration of oxygen was raised. Experiment shows that intrinsic reaction rate coefficients for combustion of various coals differ by up to four orders of magnitude at a given temperature ${ }^{16}$. Fu et al. ${ }^{17}$ reported activation energies and Arrhenius pre-exponential factors for the combustion of a great variety of coals, including high ash coals. They found that activation energy independs of type and properties of coals, varying only with temperature. Otherwise, observed that pre-exponential factors depend on both coal properties and combustion controlling mechanism.

There is considerable discussion in literature regarding kinetic models for reactions of complex materials ${ }^{18}$. In general, series of sequential and parallel uni and bi-molecular homogeneous as well as heterogeneous chemical reactions must be accounted for. In gassolid reactions such as coal combustion, for instance, there is also parallel effects on reaction due to intra-particle mass transport. Traditional kinetic models for homogeneous reactions do not appear to be suitable for reactive processes of complex materials. Therefore, the so called global kinetic analyses have been proposed, where the reactive parameters are affected by other effects besides pure homogeneous kinetics. Definitions of effective parameters such as apparent activation energy and pseudo order of reaction have been advanced. The global kinetic models may be sub-divided into conventional models and distributed reactivity models. The conventional models aim to establish constant activation energies representative of a whole reactive process in a wide range of temperatures. Friedman ${ }^{19}$, Coats and Redfern ${ }^{20}$, Michelson and Einhorn $^{21}$ and Kopsch ${ }^{22}$, among others, describe different conventional reactivity models. In general, the conventional models assume reactions of either pseudo first order or pseudo order n, and apply Arrhenius' kinetics and alike. The simpler and most popular models have been generally named power law or nth-order Arrhenius kinetic models. Also popular is the LangmuirHinshelwood kinetics, which comprises an oxygen adsorption step in the carbon active sites followed by a CO desorption step. Murphy and Shaddix ${ }^{15}$ found good fits to their empirical data for both nthorder Arrhenius and nth-order Langmuir-Hinshelwood kinetics. On the other hand, Hurt and Calo ${ }^{23}$ observe that both nth-order Arrhenius and Langmuir-Hinshelwood kinetics fail to provide even the crudest description of their data. Arrhenius' kinetics is valid for homogeneous reactions, and has only a qualitative justification for being applied to complex reactive processes ${ }^{18}$. Nevertheless, the actual state of knowledge on complex reaction kinetics has not yet provided a clearly better alternative, and Arrhenius' kinetics keeps widely applied. Kissinger ${ }^{24,25}$ and Ozawa ${ }^{26,27}$ present relevant conventional models making use of TG and DTA results for deriving kinetic data. Two different approaches may be followed for deriving kinetic parameters from thermal analysis results ${ }^{26,28}$. One of them is based on the application of thermo-analytical data on global reaction rate equations integrated over suitable ranges of temperature. In the other procedure, more common, global reaction rate expressions are converted into linear equations, and the kinetic parameters are derived through linear regression. In the distributed reactivity models distributions of activation energy are proposed as a function of temperature. Different functions are assumed such as Gausian, Weibull, Gama and even arbitrary discrete distributions. Burnham and Braun ${ }^{18}$ studied the kinetics of fossil fuels combustion applying both conventional and distributed reactivity models, and found similar results. The authors observed that conventional models of pseudo order $n$ usually produce better results than Gausian distributed reactivity models for natural materials such as coals.

Studies on chemical kinetics through thermal analysis may be carried out by either isothermal or non-isothermal methods. There is considerable literature arguing in favor of each of the procedures, having in view different reactive processes of different materials ${ }^{29}$. Non-isothermal methods have been widely applied for complex heterogeneous reactions (e.g..$^{9,10,27,28-38}$ ). Kok et al. ${ }^{39}$ and Solomon et $a l . .^{40}$ observe that non-isothermal chemical kinetic studies of coal combustion are made difficult by the presence of various complex substances in coals, and due to the high number of consecutive and parallel chemical reactions that take place. On the other side, Prasad et al..$^{29}$ observe that in isothermal analyses the materials physically change during reaction and suggests that no unique set of kinetic parameters can be derived for the whole process. Of course, nonisothermal analyses do not provide a solution for such a difficulty. In fact, at each temperature of a non-isothermal process there will be very instantaneous and well defined as well as unknown physical conditions of the materials. It is clear that, in view of the current state of knowledge, none of the techniques, isothermal or nonisothermal, is quite adequate. In this work, for the sake of simplicity, non-isothermal analysis is applied and a pseudo first order Arrhenius' kinetics is assumed. 


\section{EXPERIMENTAL}

Non-isothermal TG (thermogravimetry) was applied for determining chemical kinetic parameters in coal combustion. Activation energy and the pre-exponential factor were determined considering first order Arrhenius' kinetics. Ignition temperature was established. Also, DTA (differential thermal analysis) was applied for evaluating the homogeneous or heterogeneous character of the combustion. The thermogravimetric and thermal differential analyses were performed on Shimadzu analysers, respectively, TGA-51H and DTA-50. A particular south brazilian mineral coal from Criciúma-SC (provided by Carbonífera Metropolitana SA), was utilized. It is a raw bituminous high ash high sulfur coal from which the so called energetic coals are produced through grinding and washing. The raw mineral coal was grinded, mixed, homogenized and selected in narrow size distributions between subsequent ASTM sieves (e.g, the mean size $775 \mu \mathrm{m}$ results from passing through a sieve with $840 \mu \mathrm{m}$ aperture, and retention in a sieve with $710 \mu \mathrm{m}$ aperture).

Coal samples of $10 \mathrm{mg}$ and $775 \mu \mathrm{m}$ mean size were used in the experiments. Confidence studies on combustion extent showed those figures are suitable for TG/DTA experiments. It's been observed that such settings guarantee homogeneity of ignition and prevents decripitation (this effect was not observed for particulates bigger than $385 \mu \mathrm{m}$ mean size $)^{41}$. Gentziz and Chambers ${ }^{42}$ and De Soete ${ }^{43}$ observe that coal particulate sizes higher than $100 \mu \mathrm{m}$ and heating rates below $600{ }^{\circ} \mathrm{C} / \mathrm{min}$ favor homogeneous ignition. It is known that higher heating rates cause larger temperature gradients throughout the sample, thereby affecting kinetics (see for instance ${ }^{27,44}$ ). In this work several heating rates were used in order to evaluate its effect over kinetics.In the TG experiments heating rates between 10 and $50{ }^{\circ} \mathrm{C} / \mathrm{min}$ were applied. In the pyrolysis experiments $\mathrm{N}_{2}$ inert atmospheres were used, keeping a $110{ }^{\circ} \mathrm{C}$ isotherm until drying is finished. Then heating is resumed, and a $950{ }^{\circ} \mathrm{C}$ isotherm is kept until the process is over. In the combustion experiments synthetic air atmospheres were used, also keeping a $110{ }^{\circ} \mathrm{C}$ isotherm until the drying step is accomplished. Then heating goes on, and a $850{ }^{\circ} \mathrm{C}$ isotherm is kept until the end of fixed carbon combustion. A description of the methodology used in the experiments of pyrolysis and combustion can be found in Warne ${ }^{45}$. In the DTA experiments a heating rate of $30^{\circ} \mathrm{C} / \mathrm{min}$ was applied in sintetic air atmosphere until combustiom is finished. No different heating rates were applied. According to Yong ${ }^{7}$ the heating rate does not affect the type of ignition.

In the chemical kinetic studies it is assumed that the global combustion reaction is pseudo first order regarding the loss of weight of the sample (see for instance ${ }^{11}$ ), and zeroth order regarding the concentrations of reactive gases (which is quite adequate in view of the differential conditions that have been imposed). It follows that

$\frac{d\left(w-w_{f}\right)}{d t}=-k\left(w-w_{f}\right)$

where $\mathrm{w}$ is the instantaneous weight of the sample, $\mathrm{w}_{\mathrm{f}}$ is the residual weight of ashes after combustion is finished, $\mathrm{t}$ is the time, and $\mathrm{k}$ is the reaction rate coefficient. As $t$ is time independent,

$$
\frac{\mathrm{dw}}{\mathrm{dt}}=-\mathrm{k}\left(\mathrm{w}-\mathrm{w}_{\mathrm{f}}\right)
$$

Assuming Arrhenius' kinetics,

$$
\mathrm{k}=\mathrm{A} \exp \left[-\frac{\mathrm{E}}{\mathrm{RT}}\right]
$$

where $\mathrm{A}$ is the pre-exponential factor, $\mathrm{E}$ is the activation energy, $\mathrm{R}$ is the universal gas constant $\left(8.3145 \times 10^{-3} \mathrm{~kJ} / \mathrm{mol} \mathrm{K}\right)$, and $\mathrm{T}$ is the temperature. It should be noted that the order of reaction regarding reactant gases does not affect the activation energy but only the preexponential factor.

Still, it is assumed that the non-dimensional time loss of weight of the sample is constant at a given constant temperature. This hypothesis is required in non-isothermal transient studies so that at each instantaneous temperature it is possible to assign a determined constant value to the reaction rate coefficient. Then,

$-\frac{1}{\left(w-w_{f}\right)} \frac{d w}{d t}=A \exp \left[-\frac{E}{R T}\right]=f(T)$

Applying the natural logarithm operator to Equation 4, it follows that

$\ln \left[-\frac{1}{\left(w-w_{f}\right)} \frac{d w}{d t}\right]=\ln [A]-\left[\frac{E}{R}\right] \frac{1}{T}$

Equation 5 shows a linear relation between $\ln \left[-\frac{1}{\left(w-w_{f}\right)} \frac{d w}{d t}\right]$ and $1 / \mathrm{T}$. As a consequence, $\ln [\mathrm{A}]$ is given by the interception of the straight line with the ordinate axis as $1 / \mathrm{T}$ tends to zero, and $[\mathrm{E} / \mathrm{R}]$ is given by the inclination of the line, i.e.

$$
\begin{aligned}
& A=\left[-\frac{1}{\left(w-w_{f}\right)} \frac{d w}{d t}\right]_{\frac{1}{T} \rightarrow 0} \\
& {\left[\frac{E}{R}\right]=-\frac{d\left(\ln \left[-\frac{1}{\left(w-w_{f}\right)} \frac{d w}{d t}\right]\right)}{d\left(\frac{1}{T}\right)}}
\end{aligned}
$$

\section{RESULTS AND DISCUSSION}

Table 1 presents the elemental analysis of the coal, while Figure 1 presents its proximate analysis obtained by TG. The high ash and sulfur contents typical of the raw south brazilian coals are observed. X-ray difraction analyses indicated that sulfur is present in the compounds $\mathrm{CaSO}_{4} \cdot 2 \mathrm{H}_{2} \mathrm{O}$ and $\left(\mathrm{NH}_{4}\right)_{3} \cdot \mathrm{Fe}\left(\mathrm{SO}_{4}\right)_{3}$. Contrary to the expected, the analyses did not detect any presence of pyrite/ marcasite $\left(\mathrm{FeS}_{2}\right)$. Those compounds are generally present in coals in variable amounts. For instance, it represents in average up to about $1.7 \%$ of the total sulfur present in north american coals ${ }^{46}$, and up to $72 \%$ of the sulfur in Polish coals ${ }^{47}$. The X-ray difraction results were confirmed in repeated experiments.

Table 1. Elemental analysis of the coal (mass\%)

\begin{tabular}{lllll}
\hline $\mathrm{C} \%$ & $\mathrm{~N} \%$ & $\mathrm{O} \%$ & $\mathrm{H} \%$ & $\mathrm{~S} \%$ \\
\hline 50.59 & 0.90 & 7.93 & 3.52 & 5.14 \\
\hline
\end{tabular}

Figure 2 presents TG results on pyrolysis and combustion which were used for determining the ignition temperature. The ignition temperature is assumed to be the average temperature in the last time interval where both curves coincide ${ }^{7}$. The determination of 


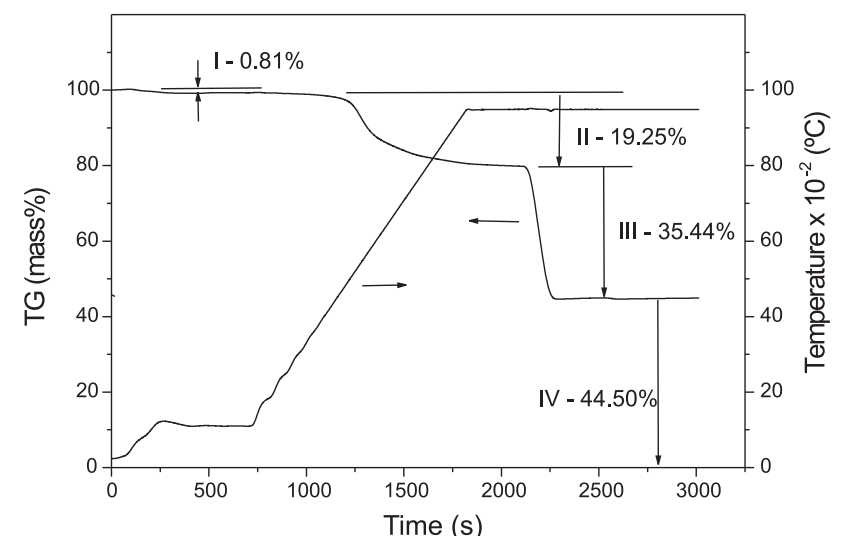

Figure 1. TG proximate analysis of the cial (I-moisture; II-volatiles; IIIfixedcarbon; $I V$-ashes)

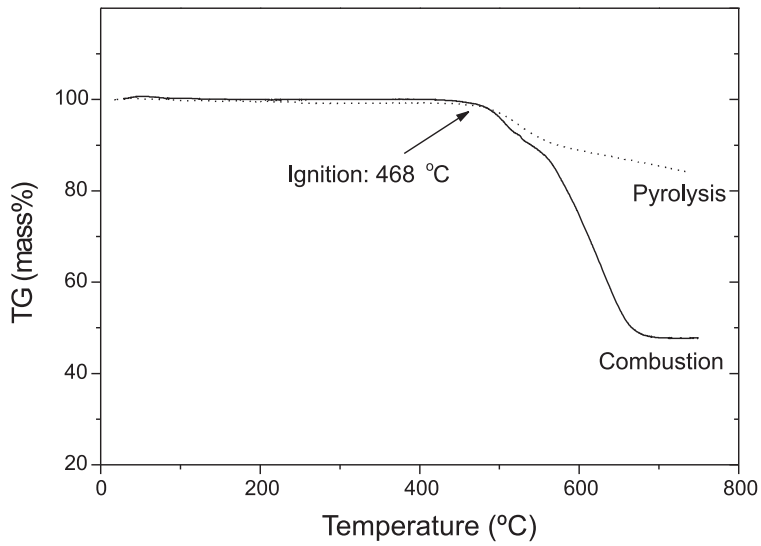

Figure 2. TG results for pyrolysis and combustion of the coal used for determining the ignition temperature

ignition temperature through TG showed to be dependent on the mass of the sample. However, a variation of $100 \%$ on the sample mass (from 10 to $20 \mathrm{mg}$ ) caused a variation of only $3 \%$ on the temperature of ignition (from 482 to $468{ }^{\circ} \mathrm{C}$ ).

Figure 3 shows DTA results of combustion which allow to evaluate about the type of ignition. Flatter curves indicate homogeneous combustion, while sharp pics are indicative of heterogeneous combustion $^{48}$. The figure shows a very sharp pic in the exothermic event, indicating a predominant heterogeneous combustion.

Figure 4 shows results of TG experiments carried out for determining the reaction rate coefficient, i.e. the pre-exponential factor and the activation energy. Figure 5 presents DTG curves obtained by time derivation of the TG curves from Figure 4. Two main reactive events take place which are identified as primary and secondary combustion $^{8}$. Those events are well characterized through the observed changes of behavior of the DTG curves from ignition, which happened around $470{ }^{\circ} \mathrm{C}$ for all the heating rates. Results showed that at higher heating rates both primary and secondary combustion are more pronounced. Also, the higher the heating rate the higher the temperature where the maximum reaction rate takes place.

For the primary combustion step it follows that

$$
\frac{\mathrm{dw}}{\mathrm{dt}}=-\mathrm{k}_{1}\left(\mathrm{w}-\mathrm{w}_{\mathrm{r}}\right)
$$

where $\mathrm{w}_{\mathrm{r}}$ is the residual weight of the sample as primary combustion is finished, and $\mathrm{k}_{1}$ is the reaction rate coefficient for the primary combustion step. For the secondary combustion step it follows that

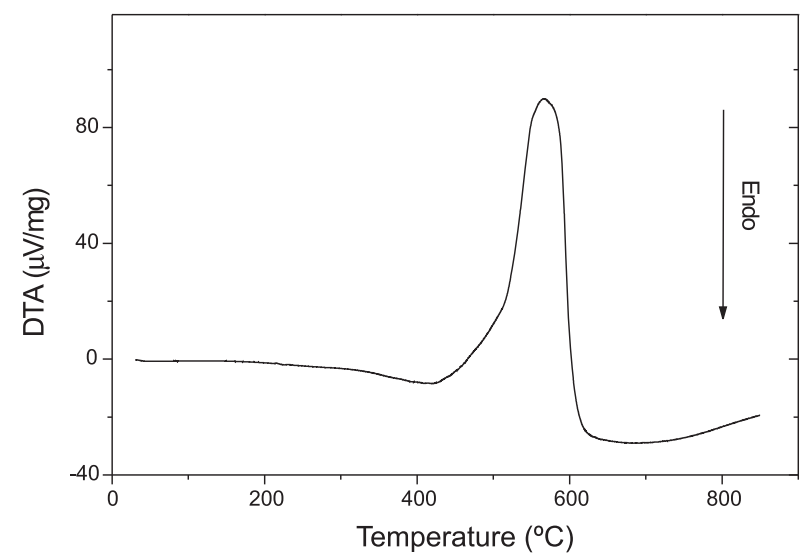

Figure 3. DTA results for combustion of the coal

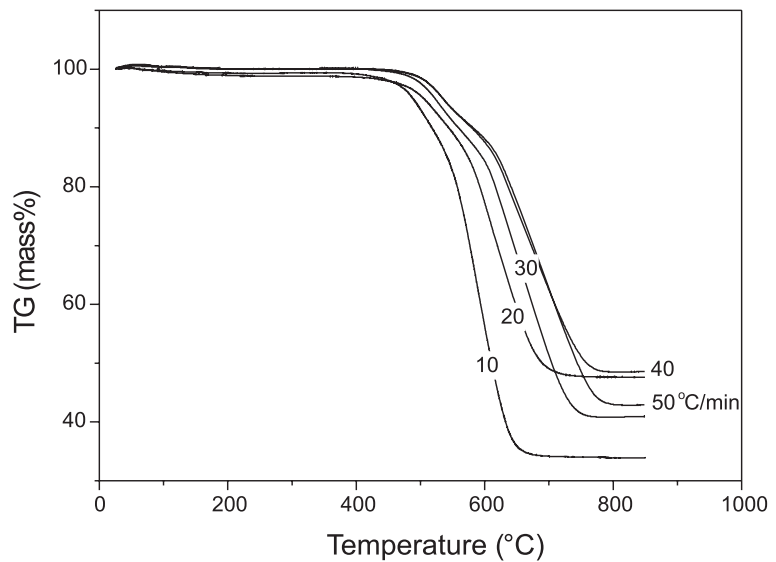

Figure 4. TG results on combustion of the coal for the chemical kinetics analysis

$\frac{\mathrm{dw}}{\mathrm{dt}}=-\mathrm{k}_{2}\left(\mathrm{w}-\mathrm{w}_{\mathrm{f}}\right)$

where $\mathrm{w}_{\mathrm{f}}$ is the residual weight of the sample as secondary combustion is finished, and $\mathrm{k}_{2}$ is the reaction rate coefficient for the secondary combustion step.

From the TG and DTG results for the various heating rates considered $\ln \left[-\frac{1}{\left(\mathrm{w}-\mathrm{w}_{\mathrm{r}}\right)} \frac{\mathrm{dw}}{\mathrm{dt}}\right]$ and $\ln \left[-\frac{1}{\left(\mathrm{w}-\mathrm{w}_{\mathrm{f}}\right)} \frac{\mathrm{dw}}{\mathrm{dt}}\right]$ are obtained as a function of $1 / \mathrm{T}$, for both primary and secondary combustion steps. Those are plotted in Figure 6. The Arrhenius analysis of the primary and secondary combustion stages were made excluding transition regions, namely from drying to primary combustion, from primary to secondary combustion, and from secondary combustion to burnout.

By applying least squares regression to both the primary and the secondary combustion regions, pre-exponential factors and activation energies are obtained. It can be observed from the plots that the higher the heating rate the lower the resulting activation energy in both combustion stages. Accounting for all the data for all the heating rates, the Arrhenius fits for the primary and the secondary combustion steps result, respectively

$$
\begin{array}{ll}
\mathrm{k}_{1}=65271 \exp \left[-\frac{135.1}{\mathrm{RT}}\right] \quad\left(\mathrm{s}^{-1}\right) \\
\mathrm{k}_{2}=8.3951 \exp \left[-\frac{85.1}{\mathrm{RT}}\right] & \left(\mathrm{s}^{-1}\right)
\end{array}
$$




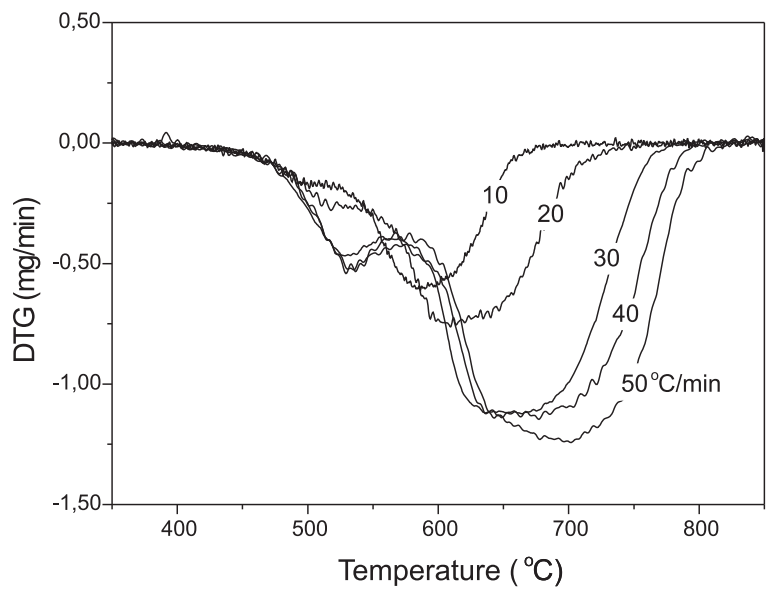

Figure 5. DTG curves obtained from the TG curves of Figure 4

Hakvoort et al..$^{49}$ observes that the stage of reaction where volatiles combustion take place (primary combustion) is characterized by lower activation energies as compared to fixed carbon combustion alone (secondary combustion). Contrary to that, in the present work the activation energy was lower for the combustion of fixed carbon alone. Such is a consequence of the transient nature of the non-isothermal experiments that have been performed, in which the physical structure of the coal is continuously changing during reaction. At higher temperatures, where secondary combustion takes place, the reaction tends to be controlled by intra-particle diffusion. As combustion proceeds carbon is continuously removed from the particles thereby opening pores and reducing diffusion resistances. A progressive conversion mode of combustion may also become dominant, thereby enlarging the fraction of a particle actually available to reaction. Those effects enhance reaction rate and contribute to a decreasing activation energy. Alongside with decreasing diffusion resistances, BET surface area is supposed to be reduced by both changing of micro and mesopores into macropores, and sintering. Considering the above trends, and in view of the presently observed reduction of activation energy in the secondary combustion stage, it appears that the effect of reducing diffusion resistances predominates over the opposite effect of loosing BET surface area. It could be argued that the higher temperatures and consequent decreased kinetic resistances would be the only reason for enhanced reaction and decreased activation energy in the secondary combustion stage. However, the proposition of a decreasing diffusion resistance suits better the results of the present work. The TG curves of Figure 4 show that the reaction rates, as primary combustion ends, quickly change to higher levels and keep mostly constant throughout the whole range of increasing temperatures as secondary combustion develops. It seems that the activation energy depends very much on the evolving particle structure, so that a correlation better than Arrhenius' should be sought if coal combustion kinetics is to be more accurately addressed.

Assuming a unique combustion step the reaction rate coefficient, obtained from the plotting of Figure 7, results

$$
\mathrm{k}=96.157 \exp \left[-\frac{104.2}{\mathrm{RT}}\right] \quad\left(\mathrm{s}^{-1}\right)
$$

Table 2 presents some literature data of activation energy on combustion of coals and chars in comparison to the present result for a brazilian coal. It is seen that the present result falls inside the common range of activation energies reported in literature, which was expected since the activation energy is supposed to be independent of coal type and properties ${ }^{17}$. Ilic et al..$^{50}$ studied the kinetics of

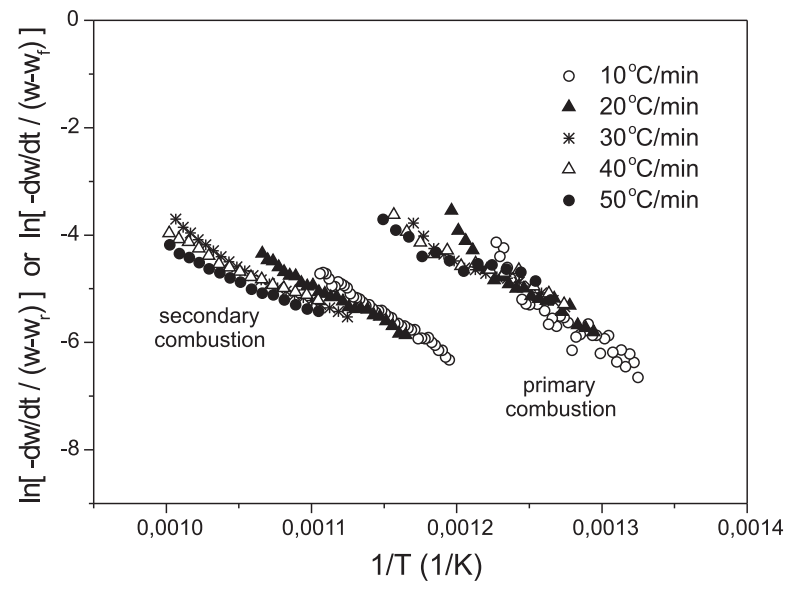

Figure 6. Arrehenius plot fo TG combustion of the coal for both primary and secondary combustion step

Table 2. Some literature data of activation energy on combustion of coals and chars considering n-th order (power law) Arrhenius kinetics

\begin{tabular}{llc}
\hline Reference & Fuel & $E^{*}(\mathrm{~kJ} / \mathrm{mol})$ \\
\hline Present Work & Brazilian bituminous & 104.2 \\
51 & Various coals and chars & 149.5 (average) \\
12 & Various coals and chars & 129.8 (average) \\
16 & Various coals and chars & $100-167$ \\
11 & Various coals and chars & $129.8-167.5$ \\
10 & LignitesBituminousAnthracites & $56-65$ \\
& & $72-114$ \\
& & $108-153$ \\
49 & Various coals & $108-142$ \\
50 & Brown coal & 93.3 \\
52 & Various coals & $120-140$ \\
53 & Various coals & $155($ average $)$ \\
30 & Two coal chars & 133,143 \\
15 & Two coal chars & $73,63.8$ \\
\hline
\end{tabular}

combustion of a high ash brown coal $(21.7 \%$ ash, $32.5 \%$ volatiles, $36.9 \%$ fixed carbon) and found an activation energy of $93.3 \mathrm{~kJ} / \mathrm{mol}$. This figure is very close to the present result of $104.2 \mathrm{~kJ} / \mathrm{mol}$ found for a high ash brazilian bituminous coal (44.50\% ash, $19.25 \%$ volatiles, $35.44 \%$ ), in spite of the differences on the proximate analysis of the two coals. Also, the present result is inside the range reported by Cumming ${ }^{10}$ for bituminous coals $(72-114 \mathrm{~kJ} / \mathrm{mol})$.

Regarding the pre-exponential factor, comparisons to literature data are quite difficult since the parameter varies widely even for the same coal in different reaction stages. Besides, it is quite dependant on the order of reaction regarding reactant gases. It is clear from Figure 7 , as well as from literature, that even very slight changes on the activation energy cause huge changes on the pre-exponential factor. In the present experiments the preexponential factor resulted $65271 \mathrm{~s}^{-1}$ for the primary combustion step, and $8.3951 \mathrm{~s}^{-1}$ for the secondary combustion step. Those numbers differ to each other by 4 orders of magnitude. Therefore, besides the dependence on coal type, the pre-exponential factor shows to be quite sensitive to the reaction stage as well.

\section{CONCLUSIONS AND REMARKS}

A TG non-isothermal chemical kinetic study was undertaken for the combustion of a brazilian raw mineral coal. DTA figures showed a very sharp pick of temperature in the exothermic event, 


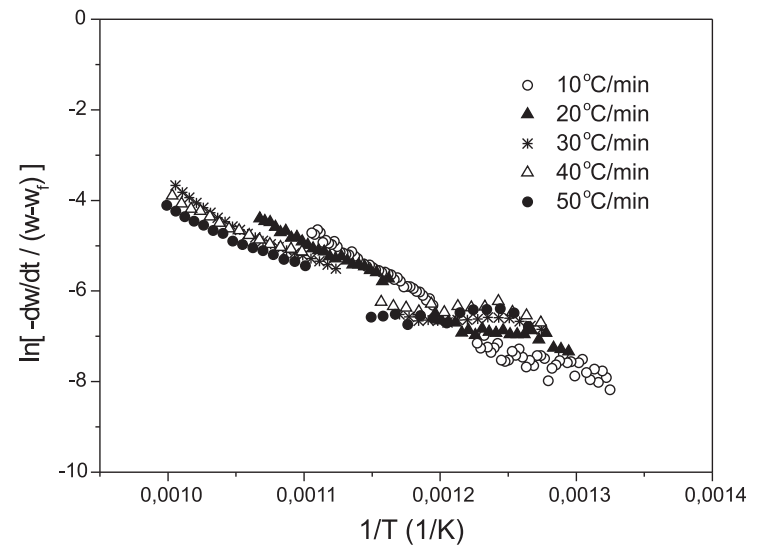

Figure 7. Arrehenius plot fo TG combustion of the coal for a unique combustion step

indicating heterogeneous combustion. X-ray difraction analyses of the coal indicated the presence of sulfur in the compounds $\mathrm{CaSO}_{4} \cdot 2 \mathrm{H}_{2} \mathrm{O}$ and $\left(\mathrm{NH}_{4}\right)_{3} \cdot \mathrm{Fe}\left(\mathrm{SO}_{4}\right)_{3}$. No pyrite $\left(\mathrm{FeS}_{2}\right)$ was found.

TG results showed that at higher heating rates both primary and secondary combustion are more pronounced. The higher the heating rate the higher the temperature where the maximum reaction rate takes place. Also, higher heating rates produced lower activation energies. Contrary to some literature data, the activation energy resulted lower during the secondary combustion stage as compared to the primary combustion step. It was concluded that such shall be a consequence of decreased intra-particle diffusion resistances owing to the changing structure of the coal particles as temperature is raised. A decreased kinetic resistance was ruled out as a cause for the enhanced reactivity in the secondary combustion step since reaction rate keeps mostly constant throughout the whole range of increasing temperatures as reaction develops.

As well known, non-isothermal studies are relevant for reactive processes where only truly kinetic effects take place. In high ash high volatile coal combustion, however, other effects happen which must be accounted for. Those are mainly related to intra-particle mass transfer and structural changes affecting the availabilitity of carbon active sites for chemical reaction. The unknown evolution of porosity and BET surface area during reaction is a major difficulty to overcome. The kinetic parameters derived in this work come from reaction rates characterized only by temperature, irrespective of mass transfer and structural transient variations. In fact, at each temperature of the process there were very instantaneous and well defined as well as unknown conditions of porosity and BET surface area. The kinetic parameters presented in this work must be approached with care since they were determined in a process under changing conditions other than temperature. Notwithstanding, the activation energies found in this work are inside the common range for coals and chars reported in literature.

\section{ACKNOWLEDGEMENTS}

This work was supported by FAPESP (São Paulo State Research Foundation) and CNPq (National Council for Scientific and Technological Development). The authors are grateful to Carbonífera Metropolitana SA for providing the raw mineral coal used in the experiments.

\section{REFERENCES}

1. Hessley, R. K.; Reasoner, J. W.; Riley, J. T.; Coal science - an introduction to chemistry technology, and utilization, Wiley-Interscience: New York, 1986.

2. Stach, E.; Mackowsky. M. T.; Teichmuller, M.; Taylor, G. H.; Chandra, D.; Teichmuller, R.; Stach's textbook of coal petrology, Gebruder Borrntraege: Berlin, 1981.

3. Parr, S. W.; J. Ind. Eng. Chem. 1922, 14, 923, included in Coal, part II scientific and technical aspects; Hawley M. E., ed., Dowden, Hutchinson \& Ross: Pennsylvania, 1976, p. 37.

4. Levenspiel, O.; Chemical reaction engineering, John Willey \& Sons: Singapore, 1972.

5. Anthony, D. B.; AIChE J. 1976, 22, 625.

6. Davini, P.; Ghetti, P.; Bonfanti, L.; De Michele, G.; Fuel 1996, 75, 1088.

7. Yong, C.; Mori, S.; Pan, W. P.; Thermochim. Acta 1996, 275, 158.

8. Crelling, J. C.; Fuel 1992, 71, 158.

9. Smith, S. E.; Neavel, R. C.; Hippo, E. J.; Miller, R. N.; Fuel 1981, 60, 462.

10. Cumming, J. W.; Fuel 1984, 63, 1440.

11. Laurendeau, N. M.; Progress in Energy and Combustion Science 1978, 4, 270.

12. Dutta, S.; Wen, C. Y.; Ind. Eng. Chem. Process. Des. Develop. 1977, 16, 30.

13. Dutta, S.; Wen, C. Y. In Coal Conversion Technology; Wen, C. Y.; Lee, E. S., eds.; Addison-Wesley, Reading: MA, 1979, p. 133-147.

14. Maloney, D. J.; Monazam, E. R.; Casleton, K. H.; Shaddix, C. R.; Proceedings of the Combustion Institute 2005, 30, 2197.

15. Murphy, J. J.; Shaddix, C. R.; Combust. Flame 2006, 144, 710.

16. Smith, I. W.; Fuel 1978, 57, 414.

17. Fu, W. B.; Zhang, B. L.; Zheng, S. M.; Combust. Flame 1997, 109, 598.

18. Burnham, A. K.; Braun, R. L; Energy Fuels 1999, 13, 22.

19. Friedman, H. L.; J. Polym. Sci. 1963, 6, 195.

20. Coats, A. W.; Redfern, J. P.; Nature 1964, 201, 69.

21. Mickelson, R.; Einhorn, T.; Thermochim. Acta 1970, 1, 158.

22. Kopsch, H.; Thermal methods in petroleum analysis, Wiley-VCH Verlag GmbH: Berlin 1998.

23. Hurt, R. H.; Calo, J. M.; Combust. Flame 2001, 125, 1138.

24. Kissinger, H. E.; J. Res. Natl. Bur. Stand. 1956, 57, 221.

25. Kissinger, H. E.; Anal. Chem. 1957, 29, 1706.

26. Ozawa, T.; Bull. Chem. Soc. Jpn. 1965, 38, 1886.

27. Ozawa, T.; J. Therm. Anal. 1970, 2, 324.

28. Heireche, L.; Belhadji, M.; Chalcogenide Letters 2007, 4, 23.

29. Prasad, T. P.; Kanungo, S. B.; Ray, H. S.; Thermochim. Acta 1992, 203, 514.

30. Everson, R. C.; Neomagus, H. W .J. P.; Kasaini, H.; Njapha, D.; Fuel 2006, $85,1076$.

31. Morgan, P. A.; Robertson, S.; Unsworth, J. F.; Fuel 1996, 65, 1551.

32. Williams, P. T.; Besler, S.; Fuel 1993, 72, 159.

33. Williams, P. T.; Besler, S.; Fuel 1995, 74, 1282.

34. Tanaka, H.; Thermochim. Acta 1995, 267, 44.

35. Chao-Hsiung, W.; Chang, C. Y.; Lin, J. P.; Hwang, J. Y.; Fuel 1997, 76, 157.

36. Zivkovic, Z.; Zivkovic, D.; Grujicic, D.; Savovic, V.; Thermochim. Acta 1998, 315, 37.

37. Conesa, J. A.; Font, R.; Fullana, A.; Caballero, J. A.; Fuel 1998, 77, 1475.

38. Senneca, O.; Salatino, P.; Chirone, R.; Fuel 1999, 78, 1575.

39. Kok, M. V.; Sobas, E.; Hicylmaz, C.; Karacan, O.; Thermochim. Acta 1997, $302,125$.

40. Solomon, P. R.; Fletcher, T. H.; Pugmire, R. J.; Fuel 1993, 72, 587.

41. Silva Filho, C. G.; Dissertação de Mestrado, Universidade de São Paulo, Brasil, 2002.

42. Gentziz, T.; Chambers, A.; Energy Sources 1995, 17, 89.

43. De Soete, G. G.; Rev. Inst. Fr. Pet 1982, 37, 352.

44. Kneller, W. A.; Thermochim. Acta 1986, 108, 357.

45. Warne, S. S. J.; Thermochim. Acta 1996, 272, 1.

46. Swanson, V. E.; Medlin, J. H.; Hatch, J. R.; Coleman, S. L.; Wood, G. H.; Woodruff, S. D.; Hildebrand, R. T.; Collection, chemical analysis and evaluation of coal samples, U.S. Dept. of the Interior Geologycal Survey; Report 76, 1976, In Raask E. Mineral Impurities in Coal Combustion; Hemisphere: New York, 1985.

47. Czaplicki, A.; Smolka, W.; Fuel Process. Technol. 1998, 55, 1.

48. Pis, J. J.; de La Puente, G.; Fuente, E.; Morán, A.; Rubiera, F.; Thermochim. Acta 1996, 279, 93.

49. Hakvoort, G.; Schouten, J. C.; Valkenburg, P. J. M.; J. Therm. Anal. 1989, 35,346 .

50. Ilic, M. S.; Oka, S. N.; Dakic, D. V. In Fluidized Bed Combustion; Heinschel, K. J., ed.; ASME: New Yourk, 1995, vol. 2.

51. Field, M. A.; Gill, D. W.; Morgan, B. B.; Hawksley, P. G. W.; Combustion of Pulverised Coal, UK, 1967.

52. Russell, N. V.; Beeley, T. J.; Man, C. K.; Gibbens, J. R.; Williamson, J.; Fuel Process. Technol. 1988, 57, 113.

53. Williams, A.; Pourkashanian, M.; Jones, J.M.; Proceedings of the Combustion Institute 2000, 28, 2141. 